\title{
Stability and forcing of the Iceland-Faroe inflow of water, heat, and salt to the Arctic
}

\author{
B. Hansen ${ }^{1}$, H. Hátún ${ }^{1}$, R. Kristiansen ${ }^{1}$, S. M. Olsen ${ }^{2}$, and S. Østerhus ${ }^{3}$ \\ ${ }^{1}$ Faroe Marine Research Institute, Nóatún 1, 100 Tórshavn, Faroe Islands \\ ${ }^{2}$ Danish Meteorological Institute, Lyngbyvej 100, 2100 Copenhagen $\varnothing$, Denmark \\ ${ }^{3}$ UNI Bjerknes and Geophysical Institute, University of Bergen, Allegaten 70, 5007 Bergen, Norway \\ Received: 6 June 2010 - Published in Ocean Sci. Discuss.: 9 July 2010 \\ Revised: 1 December 2010 - Accepted: 6 December 2010 - Published: 13 December 2010
}

\begin{abstract}
The flow of Atlantic water across the GreenlandScotland Ridge (Atlantic inflow) is critical for conditions in the Nordic Seas and Arctic Ocean by importing heat and salt. Here, we present a decade-long series of measurements from the Iceland-Faroe inflow branch (IF-inflow), which carries almost half the total Atlantic inflow. The observations show no significant trend in volume transport of Atlantic water, but temperature and salinity increased during the observational period. On shorter time scales, the observations show considerable variations but no statistically significant seasonal variation is observed and even weekly averaged transport values were consistently uni-directional from the Atlantic into the Nordic Seas. Combining transport time-series with sea level height from satellite altimetry and wind stress reveals that the force driving the IF-inflow across the topographic barrier of the Ridge is mainly generated by a pressure gradient that is due to a continuously maintained low sea level in the Southern Nordic Seas. This implies that the relative stability of the IF-inflow derives from the processes that lower the sea level by generating outflow from the Nordic Seas, especially the thermohaline processes that generate overflow. The IFinflow is an important component of the system coupling the Arctic region to the North Atlantic through the thermohaline circulation, which has been predicted to weaken in the 21st century. Our observations show no indication of weakening.
\end{abstract}

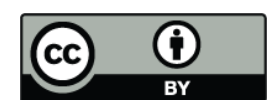

Correspondence to: B. Hansen (bogihan@hav.fo)

\section{Introduction}

The IF-inflow (Hansen and Østerhus, 2000) crosses the Iceland-Faroe Ridge (IFR) and continues in a boundary current, the Faroe Current, north of the Faroes (Fig. 1). For the 1999-2001 period, this branch was estimated to carry $45 \%$ of the total Atlantic inflow transport (Østerhus et al., 2005). We report the results of systematic temperature, salinity, and volume transport measurements from summer 1997 to summer 2008 on a standard section that crosses the Faroe Current (Fig. 1). The measurements are from an array of moored ADCPs (Acoustic Doppler Current Profilers), combined with temperature and salinity data from hydrographic surveys (Fig. 1). From these, the temporal evolution of the Atlantic water temperature and salinity has been determined, as well as daily estimates of volume transport.

The first four years of these time series have been discussed in a previous publication (Hansen et al., 2003), which describes the characteristics of the flow in detail. The details of measurements and processing are also listed in that publication. Here, we focus on the temporal variations of the full time series and the forcing mechanism. Through its transport of heat, the flow of Atlantic water across the GreenlandScotland Ridge is critical for conditions in the Nordic Seas and the Arctic Ocean and it is a component of the upper branch of the North Atlantic thermohaline circulation (THC).

The North Atlantic THC is, however, projected to weaken during the 21st century (Solomon et al., 2007), which raises the question whether the Atlantic inflow to the Nordic Seas, including the IF-inflow, also will weaken and whether that weakening has already been initiated. With a time series of

Published by Copernicus Publications on behalf of the European Geosciences Union. 

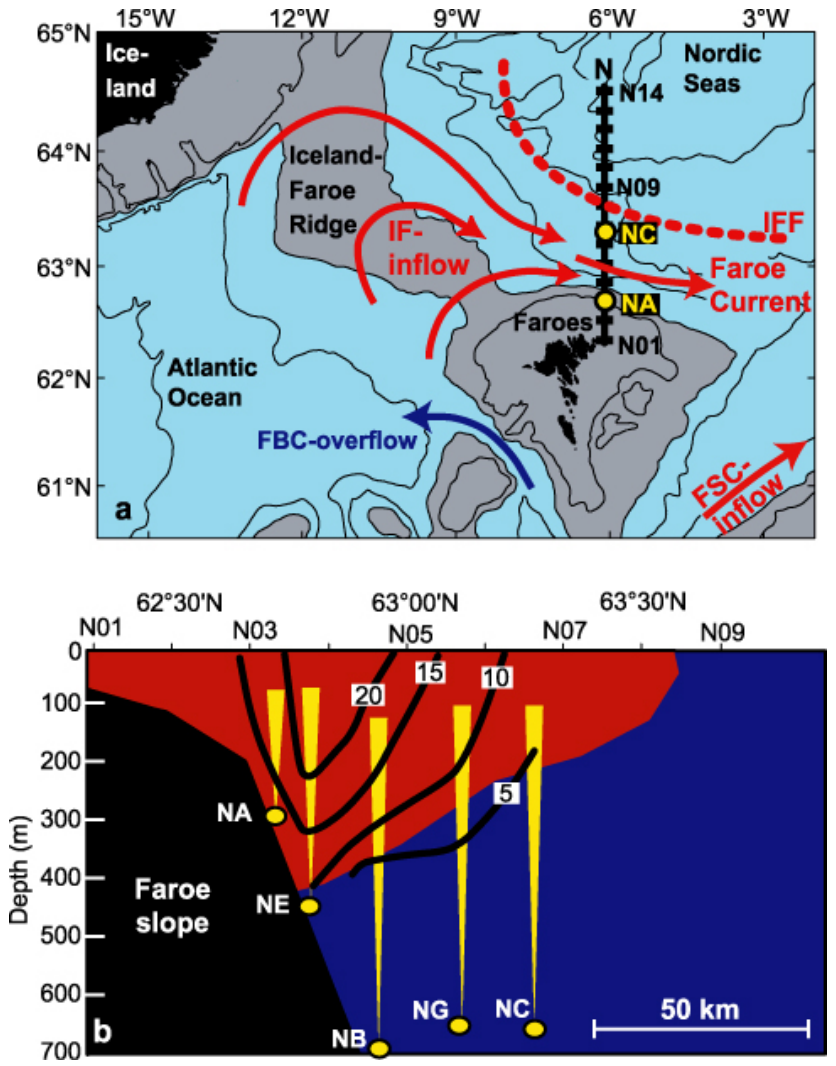

Fig. 1. Geographical setting and characteristics of the IF-inflow and observational system. (a) Bottom topography (gray areas shallower than $500 \mathrm{~m}$ ). Red arrows show the two main Atlantic inflow branches, the one across the IFR, which is bounded by the IcelandFaroe Front (IFF), and the one through the Faroe-Shetland Channel (FSC-inflow). The black line with rectangles labeled N01 to N14 is a standard section with fixed CTD stations. Yellow circles indicate the southernmost (NA) and northernmost (NC) ADCP mooring locations. Blue arrow indicates overflow through the Faroe Bank Channel (FBC-overflow). (b) The southern part of the standard section with the red area indicating water of salinity $>35.00$ on average 1997-2001 (based on Hansen et al., 2003). Thick black lines show average eastward velocities from summer 2000 to summer 2001 with values in $\mathrm{cm} \mathrm{s}^{-1}$ (based on Hansen et al., 2003). Yellow circles indicate moored ADCPs with typical ranges indicated by yellow cones.

11 years, we should be able to identify a substantial weakening, if it is occurring and, answering that question, is one of the main purposes of this study.

A more fundamental question regards the coupling between the IF-inflow and the THC. The IF-inflow feeds salt to the Nordic Seas, which helps maintain the overflow and the THC, but is there also a causal link from the THC to the IF-inflow? Such a link is implicit in the feedback mechanism (Stommel, 1961) often suggested to couple the Nordic Seas to the THC, but it requires that the force maintaining the IF-inflow is somehow linked to the THC. Most upper- layer flows are forced by wind stress and wind stress over the Northeast Atlantic has also been claimed to force the Norwegian Atlantic Current (Orvik and Skagseth, 2003). It is not obvious, however, how wind stress would depend on the THC and be an element in a feedback mechanism.

For the future fate of the IF-inflow, the dominant driving force is therefore important and we attempt to identify it by comparing our measurements of Atlantic water volume transport to data that represent the two possible forcing mechanisms: wind stress, and a cross ridge pressure gradient induced by sea level slopes. Based on this, we discuss the causal linkage between IF-inflow and the THC.

\section{Material and methods}

The results of this study are mainly based on measurements on a standard section along $6^{\circ} 05^{\prime} \mathrm{W}$ that crosses the IFinflow (Fig. 1). For the interpretation of the results, we have exploited a number of auxiliary data sources.

\subsection{Measurements on the standard section}

Since 1988, regular cruises have been carried out, usually at least four times a year, with CTD (Conductivity Temperature Depth) profiles obtained at 14 standard stations on the section. In this study, we focus on the temperature and salinity values at the core of the Atlantic water on the section from each cruise. The core was defined as that $50 \mathrm{~m}$ deep layer, which had the highest salinity on the section. Core temperature and salinity were then computed as the averages for that layer.

Since 1997, the data set has been augmented by measurements from ADCPs, moored along the standard section (Fig. 1). From summer 1997 to summer 2008, there have continuously been at least 3 and usually 4 ADCPs, except for short servicing periods every summer. The moorings were located so that the ADCPs could profile into the Atlantic water, most of which has salinities $>35.00$ (Fig. 1b), and designed to be relatively safe from fisheries. Until summer 2000, mooring NC was the northernmost, after which this mooring was moved farther south and renamed NG.

From the ADCP measurements, daily estimates of the total volume transport through the standard section can be generated, but this includes some water that has not come directly from the Atlantic. The Atlantic water that has passed directly from the IFR to the standard section has, however, water mass characteristics that are quite different from the other water masses on the section and this allows the Atlantic water component of the flow to be distinguished from the rest.

In a previous analysis (Hansen et al., 2003) of the 19972001 data, the ADCP measurements were combined with hydrographic measurements from 45 CTD cruises along this section to produce daily estimates of volume transport of Atlantic Water, defined as water that has passed directly from 

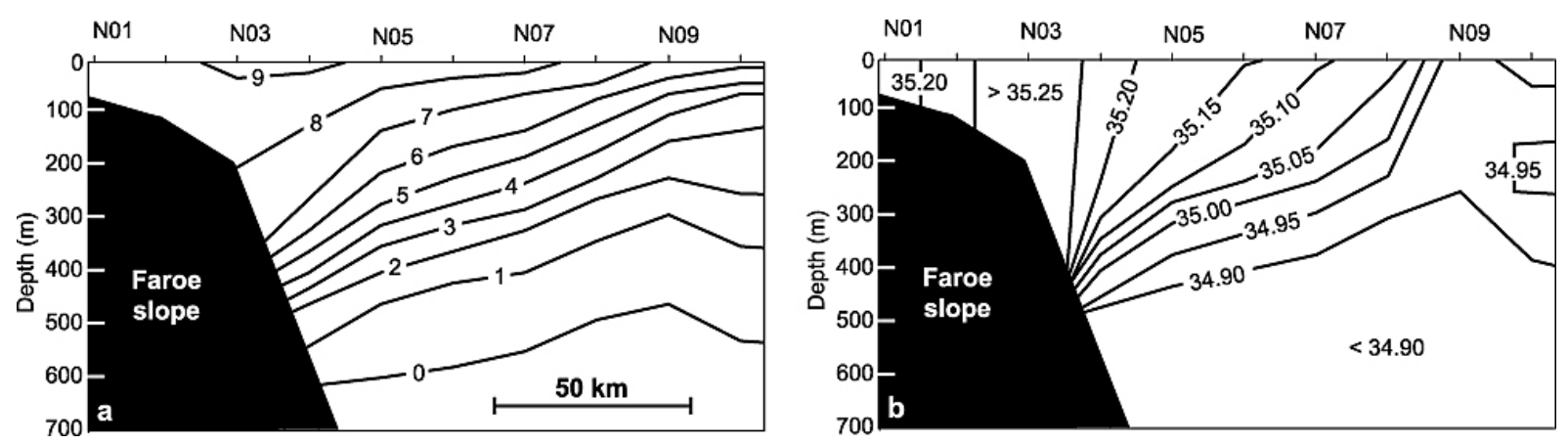

Fig. 2. Average temperature (a) and salinity (b) distribution on the standard section, based on 46 CTD cruises 1997-2008.

the IFR to the standard section. It was shown that the baroclinic part of the hydrographic fields to a large extent can be deduced from the velocity field measured by the ADCPs by using an inverse dynamic method (Hátún et al., 2004). This allows determination of the Atlantic water transport through the standard section from the ADCP measurements alone and it has been shown (Hansen et al., 2003) that this is a good measure of the Atlantic water that has passed across the IFR. In the following, the word "IF-inflow" is used to refer to this Atlantic water transport as well as to the flow more generally.

\subsection{Auxiliary data}

To illustrate the character of Atlantic water flow on the IFR and upstream of it, we used unpublished current velocity time series measured by four ADCPs that we have moored in trawl-protected frames at strategic locations for sufficiently long periods to give a representative picture.

We also use time series of volume transport of overflow water through the Faroe Bank Channel that are estimated from moored ADCPs in the channel as described in detail by Hansen and Østerhus (2007).

In order to study the forcing mechanisms of the IF-inflow, we acquired two data sets from the internet. Monthly averaged wind stress series were obtained from the NCEP/NCAR Reanalysis Project (http://www.esrl.noaa.gov/) (Kalnay et al., 1996). In addition, weekly averaged sea level height (SLH) data were acquired from AVISO (http://www.aviso. oceanobs.com). These Mapped Sea Level Anomaly (MSLA) data combine altimeter data from TOPEX/Poseidon, Jason1, EnviSat, and GeoSat and map these onto a $1 / 3^{\circ}$ Mercator grid. Weekly and monthly (four weeks) averages of IF-inflow were generated so that they were synchronous with the SLH and wind stress data. Annual averages were computed by averaging over ADCP deployment periods.

To determine seasonal variation and allow statistical testing, modified weekly averaged series of IF-inflow and SLH were produced. Gaps in the transport series were first filled by linear interpolation. High-passed versions were then computed for all the weekly averaged series by subtracting the running mean of 51 weeks. Seasonal variations were deter- mined by linear regression of these high-passed series on sinusoidal signals with the phase lag varied to give maximal correlation coefficients. De-seasoned high-passed time series were constructed by subtracting the resulting sinusoidal signal from the high-passed time series. To eliminate any remaining serial correlation, the series were furthermore "prewhitened" (von Storch and Zwiers, 1999) before testing for statistical significance.

\section{Observational results}

The typical properties on the inner part of the standard section are illustrated by average temperature and salinity distributions in Fig. 2. The Atlantic water, characterized by high temperatures and salinities, is found in a wedge-shaped area that extends down to the sill depth of the IFR in the southern end. In the northern end, it reaches the surface in the IcelandFaroe Front (Fig. 1a) just south of standard station N09 at $63^{\circ} 40^{\prime} \mathrm{N}$. The Atlantic water has, however, been strongly admixed by colder and fresher water in the deeper parts of the wedge.

The total volume transport (IF-inflow plus other water masses) through the standard section from $62^{\circ} 25^{\prime} \mathrm{N}$ to $63^{\circ} 35^{\prime} \mathrm{N}$ and from the surface down to $600 \mathrm{~m}$ depth was estimated at $4.65 \mathrm{~Sv}\left(1 \mathrm{~Sv}=10^{6} \mathrm{~m}^{3} \mathrm{~s}^{-1}\right)$ on average for the period. The seasonal variation of the total volume transport had an amplitude of $0.73 \mathrm{~Sv}$ with maximum in March.

The average IF-inflow for the 1997-2008 period was $3.5 \mathrm{~Sv}$, which is equal to the value found by Hansen et al. (2003) for the 1997-2001 period. They estimated the uncertainty to be $\pm 0.5 \mathrm{~Sv}$ for this method. Plotting the IFinflow versus the month of observation (Fig. 3a) indicates larger variability during winter months with February having both the highest and the lowest value, but a consistent seasonal variation of the IF-inflow is not evident. A seasonal signal may be masked by variations on longer time scales, but even after removing a 51 week running mean (Sect. 2.2), the best fit of the high-passed time series to a seasonal sinusoidal function only had a weak correlation (correlation coefficient 0.11$)$ and a small seasonal amplitude $(0.16 \mathrm{~Sv})$. This 

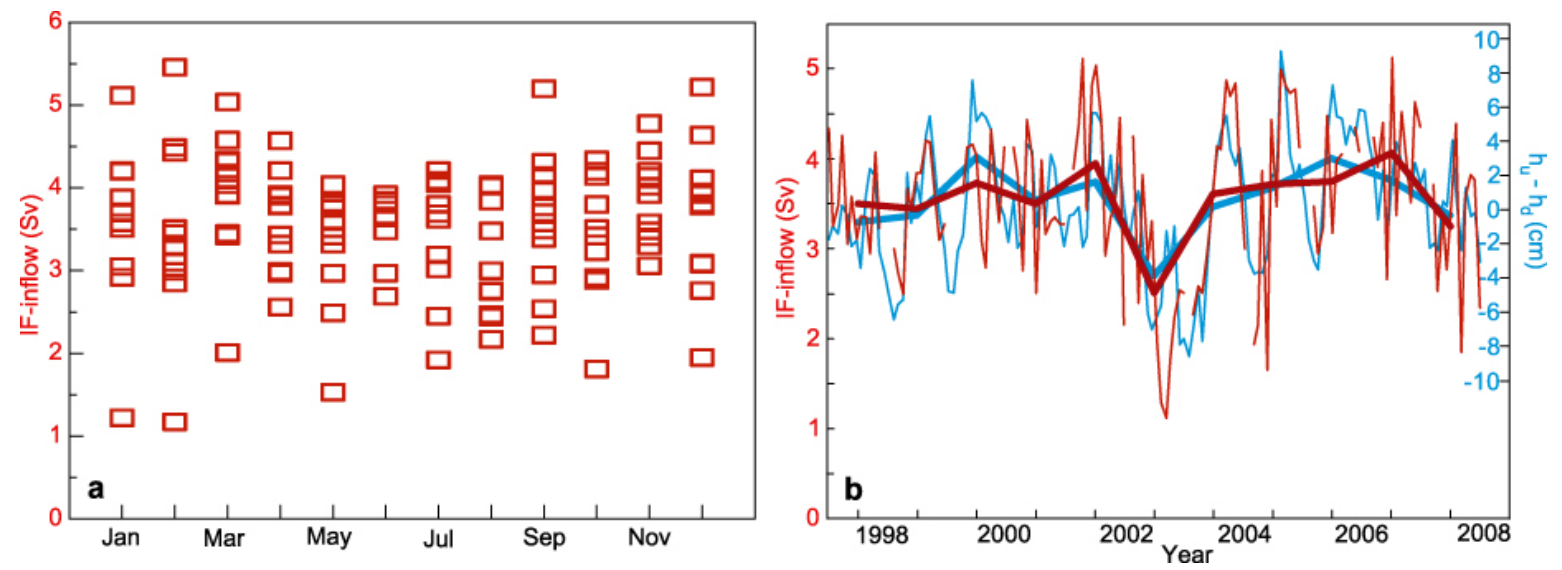

Fig. 3. Volume transport of Atlantic water across the IFR (red) plotted against the month (a) and time (b) of observation. On (b), the blue curves show the SLH difference across the IFR as measured by $h_{\mathrm{u}}-h_{\mathrm{d}}$ (defined in Fig. 11). Thin lines: monthly (four weeks) averages. Thick lines: annual averages (summer to summer).
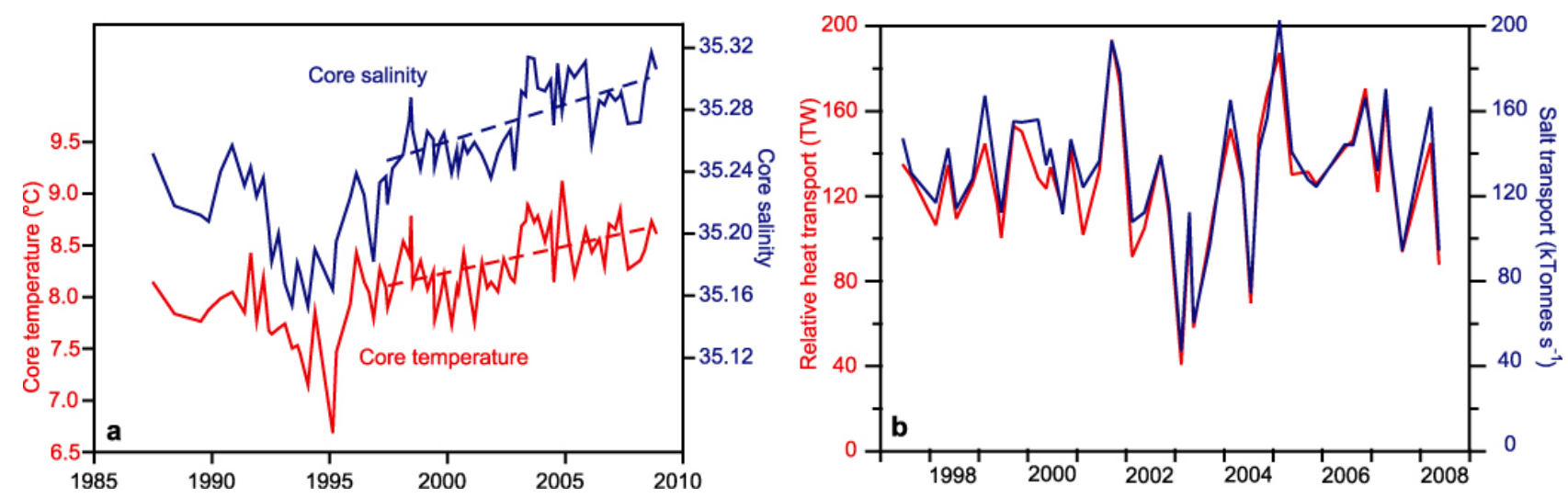

Fig. 4. (a) Temperature (red) and salinity (blue) in the core of the Faroe Current based on hydrographic surveys along the standard section. The typical seasonal variation was subtracted from the data before plotting. Broken lines indicate the trend from summer 1997 to summer 2008 based on linear regression. (b) Transport of relative heat (red) in TW $\left(10^{12} \mathrm{~W}\right)$ and salt (blue) in $\mathrm{kTonnes} \mathrm{s}^{-1}\left(10^{6} \mathrm{~kg} \mathrm{~s}^{-1}\right)$.

confirms earlier findings that the seasonally phase-locked variation of the IF-inflow is negligible (Hansen et al., 2003).

During the first three years of observation, there was an increasing trend in the annually averaged IF-inflow (Fig. 3b). This was followed by a pronounced dip during the summer 2002-summer 2003 measurements, after which the IFinflow recovered. The end of the series again indicates a weakening, but less dramatic. For the whole 1997-2008 period, regression analysis reveals a weak positive trend $\left(0.007 \pm 0.044 \mathrm{~Sv} \mathrm{yr}^{-1}\right.$ with $95 \%$ confidence interval), not significantly different from zero.

The analysis allows us to put limits on a possible trend hiding in the data noise. From the confidence interval, it follows that there is only a $2.5 \%$ probability of a decadal weakening exceeding $0.37 \mathrm{~Sv}$, or $10 \%$ of the average. This result shows that the IF-inflow has not been substantially weakened during the observational period, which is also the case for the FBCoverflow (Hansen and Østerhus, 2007), another key compo- nent of the THC. This is also consistent with modeling results that have indicated a fairly stable total overflow from 1948 to 2005 (Olsen et al., 2008).

Annual, monthly, and weekly, averaged IF-inflow was consistently positive, i.e. directed from the Atlantic into the Nordic Seas with annual means ranging from 2.5 to $4.1 \mathrm{~Sv}$ (Fig. 3b). This is in contrast to the Atlantic inflow west of Iceland (Astthorsson et al., 2007) and the inflow to the Barents Sea (Ingvaldsen et al., 2002), and is the motivation for denoting the IF-inflow a relatively stable flow.

The temperature and salinity in the core of the Atlantic water on the standard section both have increased from a minimum around 1995 (Fig. 4a). During the 1997-2008 period, the annual increase was $0.05 \pm 0.025^{\circ} \mathrm{C} \mathrm{yr}^{-1}$ in temperature and $0.005 \pm 0.0017 \mathrm{yr}^{-1}$ in salinity with $95 \%$ confidence intervals. These increases were during a period of anthropogenic global warming, but they are most likely caused by the westward retraction of the subpolar gyre (Hakkinen 

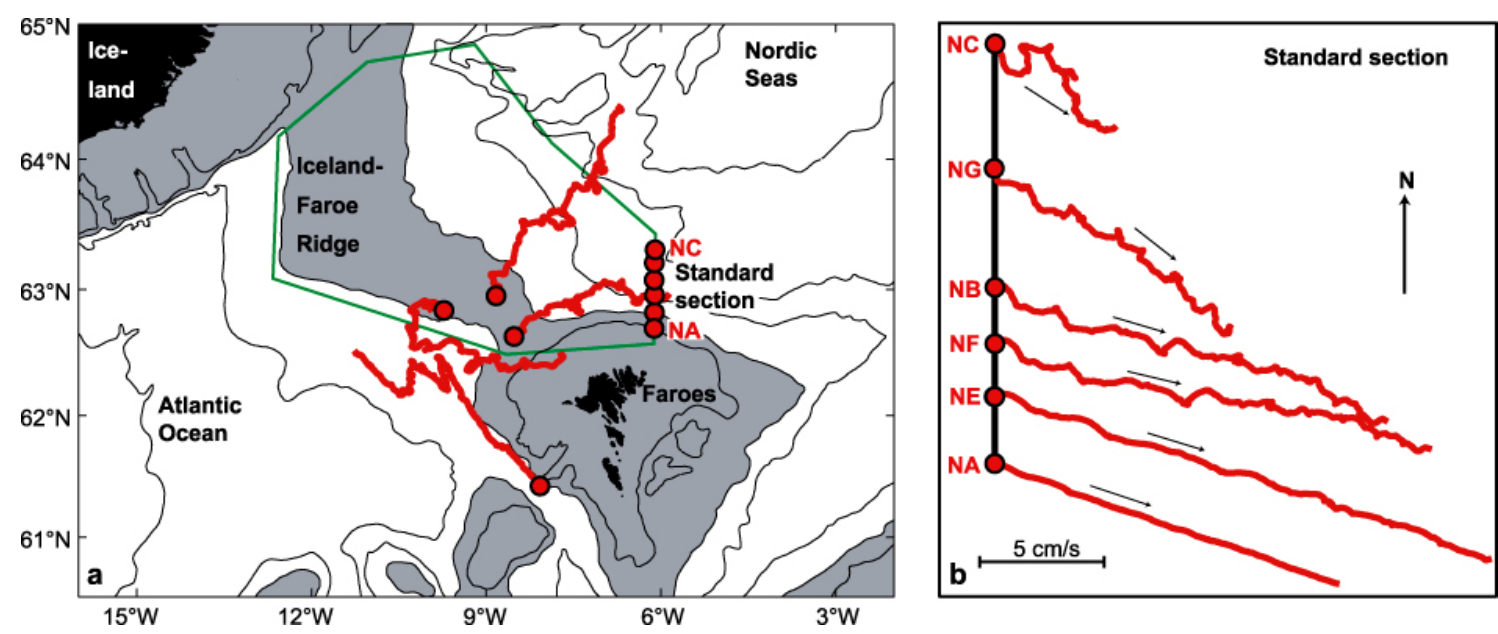

Fig. 5. Progressive vector diagrams for the flow at $225 \mathrm{~m}$ depth from 4 moored ADCPs (Acoustic Doppler Current Profilers) upstream of or on the IFR (a) and from 6 moored ADCPs on the standard section (b). The records are from different periods and have different durations between 8 and 12 months. Mooring locations are shown as red circles, from which the progressive vector diagrams extend as red traces. The progressive vector diagrams have been scaled to show the residual velocities in the scale shown on (b). The region bounded by green lines on (a) was used for calculating the flushing time from upstream to the standard section (Appendix A).

and Rhines, 2004) and the increased influence of the warmer and more saline subtropical gyre (Hátún et al., 2005).

Since the volume transport of the IF-inflow, its core temperature, and its core salinity all had positive trends, one might perhaps expect increasing heat and salt transports. For a non-closed system, heat transport is not well defined (Schauer and Beszczynska-Möller, 2009), but a relative value can be calculated by using a reference temperature, e.g. $0^{\circ} \mathrm{C}$, which is a typical outflow temperature. Combining the continuous volume transport series with discontinuous temperature and salinity data from CTD cruises is still not trivial, but estimates of salt transport and relative heat transport may be obtained by multiplying the volume transport of Atlantic water by the core salinity and temperature, respectively. This is done using monthly mean volume transport values for the months with CTD cruises. The variability in the resulting series (Fig. 4b) is dominated by the variability of the volume transport and shows no significant trends.

\section{Local forcing of the IF-inflow}

The IF-inflow is affected by forces with components perpendicular, as well as parallel, to the flow. In the direction perpendicular to the flow, we expect geostrophic balance to apply for periods above one to a few days, with the Coriolis force balanced by cross-flow pressure gradients generated by sea level and isopycnal slopes. Forces acting parallel to the flow direction will, on the contrary, change the energy of the flow and may either accelerate or retard it. We consider a force to be a "driving force", if it imparts positive energy to the flow. Such a force may be generated remotely, locally, or both.

\subsection{The evidence for local forcing of the IF-inflow}

The passage of water across the IFR has been studied with Lagrangian methods, using both near-surface drifters (Jakobsen et al., 2003) and deeper (RAFOS) floats (Rossby et al., 2009). These studies indicate some disagreement on the preferred paths across the IFR, but they do agree that water crosses the IFR as a broad flow along its entire length $(\approx 300 \mathrm{~km})$. Upstream (southwest) of and over the IFR, the Lagrangian flow paths are irregular, dominated by mesoscale activity, and fairly sluggish. After crossing the Ridge, the Atlantic water flow changes character. It becomes focused into a narrow $(\approx 100 \mathrm{~km}$ width in the surface) current with almost uni-directional flow of fairly high speed in the core.

This picture is consistent with the available data from moored instrumentation (Fig. 5). Progressive vector diagrams in the core of the Atlantic water on the standard section show velocities that are considerably higher and more directionally stable than on the IFR and upstream of it. This is also consistent with the fact that the cross-sectional area covered by Atlantic water over the crest of the IFR is almost an order of magnitude larger than the area on the standard section.

In order for water to pass across the IFR, it has to cross a steep topographic barrier, which must involve considerable upwelling and layer compression (Rossby et al., 2009) and generate vorticity. From the Ridge area to the standard section, the flow is accelerated and focused into the narrow high-speed Faroe Current (Fig. 5). This cannot occur without some kind of local forcing. The inflow stability, furthermore, indicates that this force must act uni-directionally from the Atlantic towards the Nordic Seas with no reversals on time scales from a few days up to a decade. 


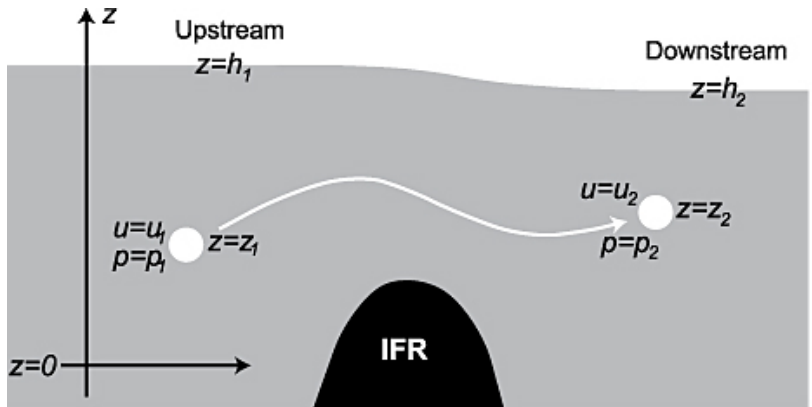

Fig. 6. Sketch illustrating the passage of a water parcel (white circle) across the IFR along an arbitrary path (curved white arrow) with $u$ representing speed, $p$ representing pressure, and $z$ representing height of the parcel above a geopotential surface (Gill, 1982).

\subsection{Theory}

To explore the local driving force, we use energy conservation in a Newtonian framework. Consider a water parcel of unit volume that initially is at a level $z_{1}$ on the upstream side of the IFR (Fig. 6). We assume that the parcel is then transported across the IFR along some path, ending up at a level $z_{2}$ downstream of the IFR, but without changing its water mass properties so that the density $\rho$ is constant. Energy conservation then allows us to relate the final speed $u_{2}$ of the parcel to its initial speed $u_{1}$ :

$$
1 / 2 \rho u_{2}^{2}+\rho g z_{2}+p_{2}=1 / 2 \rho u_{1}^{2}+\rho g z_{1}+p_{1}+w
$$

where $p_{1}$ and $p_{2}$ are the pressure of the parcel at its initial and final location, respectively. The term $w$ represents the work of other forces, e.g. wind or friction, done on the parcel along its path across the IFR. In principle, it also includes work done by the Coriolis force, but that force is always perpendicular to the flow and, hence, does no non-zero work that can affect the kinetic energy. If $w$ is zero, Eq. (1) reduces to the Bernoulli equation on a rotating earth (Gill, 1982). To get a basic understanding of the process, we now introduce a model that involves several simplifying assumptions. Firstly, we assume that the SLH upstream of the IFR can be represented by one parameter, $h_{\mathrm{u}}$, that varies with time, but is representative for all the water in the immediate area just upstream of the IFR. This seems justified from the altimetry (Fig. 7).

The second approximation involves the character of the flow through the standard section, downstream of the IFR (Fig. 1). In the model, we assume that the Atlantic water is clearly separated from the other water masses on the section in an area that can be approximated by a triangle and that it has a homogeneous density and a spatially uniform, but temporally varying, speed, $u$ (Fig. 8). In Appendix A, it is shown that Eq. (1) together with geostrophy then leads to an

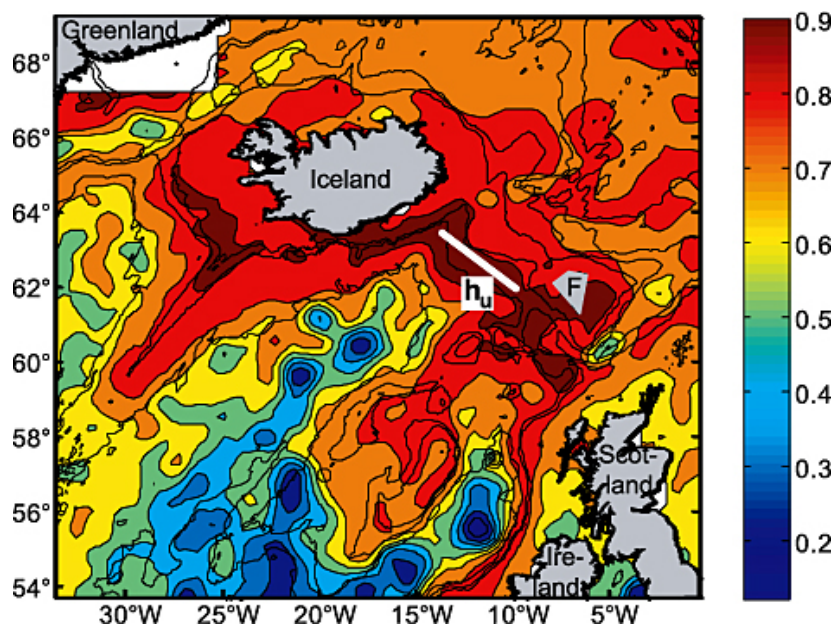

Fig. 7. Correlation coefficients between monthly averaged SLH on the white line $\left(h_{\mathrm{u}}\right)$ and SLH in altimeter grid points.

expression for the volume transport, $q$, through the standard section:

$q=\frac{9 g D}{10 f}\left(h_{\mathrm{u}}-h_{\mathrm{d}}\right)+\frac{9}{5 \rho f B} W \equiv \alpha\left(h_{\mathrm{u}}-h_{\mathrm{d}}\right)+\beta W$

where $h_{\mathrm{d}}$ is the SLH just north of the section, $B$ is the width and $D$ the maximum depth of the section (Fig. 8). $W$ is the integrated work along the path done by wind and friction on the water in a slice of the section of unit thickness, $f$ is the Coriolis parameter and the two parameters, $\alpha$ and $\beta$ are defined by this equation representing the sensitivity to sea-level and wind forcing, respectively. From the equations of motion, the local driving force can be generated by only two mechanisms: local wind stress (wind forcing) and a sea level drop across the IFR (sea level forcing) inducing a cross-ridge pressure gradient force. These two mechanisms are implicit in the two terms on the right hand side of Eq. (2) and are discussed in the following sections.

\subsection{IF-inflow response to local wind forcing}

The spatial variation of wind stress over the local IFR region is small on monthly time scales. Thus, spatially derived products, such as wind stress curl, that are so important for the circulation within basins, are not particularly meaningful in this case where we study the exchange between two basins. Instead, we apply the framework of Sect. 4.2, where the effect of local wind forcing on the IF-inflow is through the work it does on the water as it passes across the IFR and to the standard section, the last term in Eq. (2). From basic physics, this work must be proportional to the wind stress in the direction of the flow, which is mainly eastward. We, therefore, have inspected the two NCEP/NCAR wind stress components from a point on the IFR for the same period as the volume transport measurements (Fig. 9). 

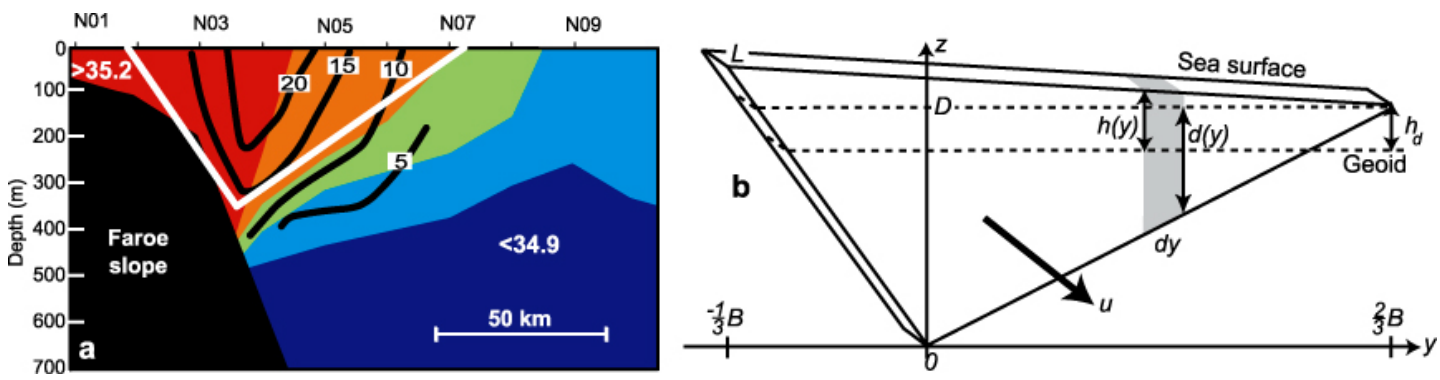

Fig. 8. Model geometry and notation. (a) The white lines indicate the triangular model geometry superposed on the typical salinity (background colours, based on Fig. 2b) and eastward velocity (based on Hansen et al., 2003) distributions. (b) A slice of Atlantic water in the model of thickness $L(D=350 \mathrm{~m}, B=100 \mathrm{~km})$.

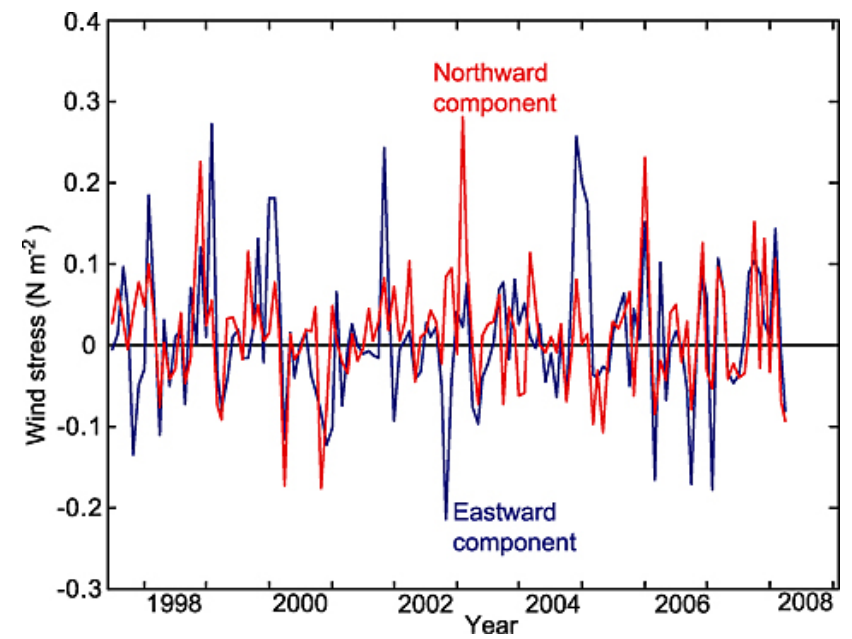

Fig. 9. Monthly averaged eastward (blue) and northward (red) components of the wind stress at position $64^{\circ} \mathrm{N}, 11^{\circ} \mathrm{W}$ from July 1997 to April 2008.

Both components of the wind stress vector vary considerably through the period with frequent reversals. Local wind forcing, therefore, cannot explain the average IF-inflow and its high stability with no reversals. Local wind stress might, however, still force the variations in IF-inflow, but with a delay on the order of a month (Appendix A). Consistent with this, the correlation coefficient between eastward wind stress and monthly mean IF-inflow is largest $(0.28)$ when the wind stress leads by a month (Fig. 10), but the correlation is weak and barely significant at the $1 \%$ level, even when no account is taken of serial correlation.

\subsection{IF-inflow response to sea level forcing}

Monthly and annually averaged SLH differences across the IFR are compared with the monthly mean IF-inflow time series (Fig. 3b, Table 1). Two indices for upstream (southwest), $h_{\mathrm{u}}$, and downstream, $h_{\mathrm{d}}$, SLH were determined by averaging SLH along two lines upstream and downstream of the IFR, respectively (Fig. 11). Monthly (four weeks) and annual

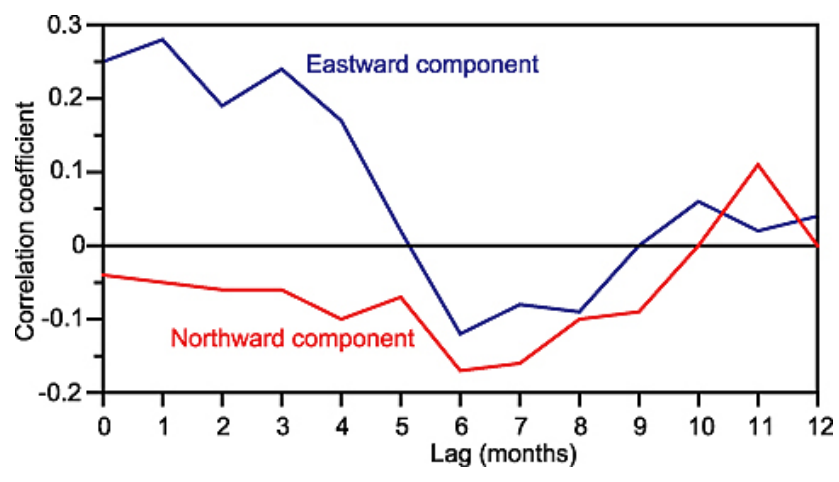

Fig. 10. Correlation coefficients between monthly averaged eastward (blue) and northward (red) components of the wind stress at position $64^{\circ} \mathrm{N}, 11^{\circ} \mathrm{W}$ and measured IF-inflow with the IF-inflow lagging behind the wind stress from 0 to 12 months.

mean values of the difference between them $\left(h_{\mathrm{u}}-h_{\mathrm{d}}\right)$ correspond well with the observed IF-inflow variations (Fig. 3b) with correlation coefficients of 0.63 for monthly and 0.87 for annual values (Table 1).

The annual data have no appreciable serial correlation and the correlation coefficient of 0.87 is statistically significant at the $1 \%$ level. To check the statistical significance at shorter time scales, we correlated the modified weekly series of IFinflow and $h_{\mathrm{u}}-h_{\mathrm{d}}$ from which inter-annual and seasonal variations had been removed and remaining serial correlation removed by pre-whitening (Sect. 2.2). Although smaller (Table 1), the correlation coefficient is still highly significant $(p<0.01)$, indicating that the relationship between IF-inflow and $h_{\mathrm{u}}-h_{\mathrm{d}}$ persists on time scales from a few days to years.

From Table 1, it is evident that the good correlation stems especially from the area downstream of the IFR and correlation between the IF-inflow and SLH in individual altimeter grid points reveals a negative correlation between the IFinflow and SLH over a wide area downstream (northeast) of the IFR (Fig. 11).

The regression coefficients (Table 1) may be compared with the theoretical value ( $\alpha$ in Eq. 2), based on the model 
Table 1. Correlation coefficients $(R)$ and proportionality factor $\alpha$ in Eq. (2) (in Sv cm ${ }^{-1}$ ) between IF-inflow and various indices for SLH based on weekly, monthly (four weeks), and annually averaged values. The last two columns (modified series, Sect. 2.2) show correlation coefficients between "pre-whitened" (von Storch and Zwiers, 1999), de-seasoned, high-pass filtered, weekly averaged series and their statistical significance.

\begin{tabular}{|c|c|c|c|c|c|c|c|c|}
\hline \multirow{3}{*}{ Index } & \multicolumn{6}{|c|}{ Raw series } & \multicolumn{2}{|c|}{ Modified series } \\
\hline & \multicolumn{2}{|c|}{ weekly } & \multicolumn{2}{|c|}{ monthly } & \multicolumn{2}{|c|}{ annual } & \multirow[b]{2}{*}{$R$} & \multirow[b]{2}{*}{ signif. } \\
\hline & $R$ & $\alpha$ & $R$ & $\alpha$ & $R$ & $\alpha$ & & \\
\hline$h_{\mathrm{u}}$ & -0.13 & -0.03 & -0.19 & -0.04 & -0.29 & -0.07 & 0.00 & n.s. \\
\hline & -0.39 & -0.07 & -0.50 & -0.07 & -0.72 & -0.10 & -0.16 & $p<0.01$ \\
\hline$h_{\mathrm{u}}-h_{\mathrm{d}}$ & +0.48 & +0.13 & +0.63 & +0.15 & +0.87 & +0.19 & +0.17 & $p<0.01$ \\
\hline
\end{tabular}

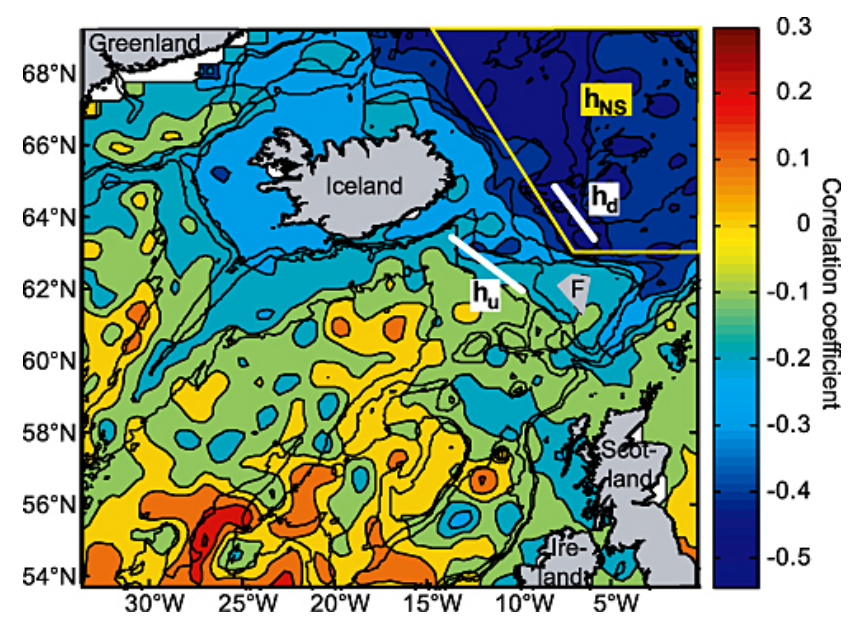

Fig. 11. Correlation coefficients between monthly averaged IFinflow and SLH in altimeter grid points. White lines indicate grid points used for defining $h_{\mathrm{u}}$ and $h_{\mathrm{d}}$, respectively and the area bounded by yellow lines is the Nordic Seas region, over which the average $\mathrm{SLH}, h_{\mathrm{NS}}$, was computed. Land areas are gray with an "F" indicating the Faroe Islands and bottom contours are shown by black lines.

in Appendix A. With the value for $D$ in Fig. 8 (350 m), the theoretical value for $\alpha$ becomes $0.24 \mathrm{~Sv} \mathrm{~cm}^{-1}$. This is somewhat higher than the regression coefficients, especially for weekly and monthly averaged data, but for annual averages, the discrepancy is small, when taking into account the simplifying assumptions of the model.

\section{Mass balance of the Nordic Seas}

In the long term, the import of water to the Nordic Seas by the IF-inflow must be balanced by an equally large net outflow (total outflow minus other inflows) from the region. On shorter time scales, there will be imbalances between the IF-inflow and the net outflow, which will lead to sea level changes whose magnitude will depend on the area. If the region directly affected by the inflow, $q$, has an area $A$, and the outflow from the region is denoted $Q$, then continuity implies:

$\frac{d h_{\mathrm{d}}}{d t}=\frac{1}{A}(q-Q)$

where it is assumed that $h_{\mathrm{d}}$ represents the average SLH over the area. Equations (2) and (3) can then be combined to give:

$\frac{d h_{\mathrm{d}}}{d t}+\frac{1}{\tau} h_{\mathrm{d}}=\frac{1}{\tau} h_{\mathrm{u}}+\frac{\beta}{A} W-\frac{Q}{A} \quad$ where $\quad \tau=\frac{A}{\alpha}$

This equation describes a system that will respond with a delay (the response time, $\tau$ ) to changes in external forcing. The value of $\tau$ depends on the area chosen to define $A$. This area should in any case encompass the region bounded by yellow lines in Fig. 11. The average SLH over this region, $h_{\mathrm{NS}}$, is highly correlated with $h_{\mathrm{d}}(R=0.96)$ and the correlation coefficient between $h_{\mathrm{NS}}$ and IF-inflow is -0.42 , using monthly averages.

Choosing the whole of the Nordic Seas, gives about $30 \mathrm{~h}$ for the response time, which ought to be an upper bound. The rapidity of this response might seem surprising, but it can be justified by a simple calculation. From the altimeter data, the standard deviation of $h_{\mathrm{u}}-h_{\mathrm{d}}$ is $\approx 3 \mathrm{~cm}$ for weekly averaged data. This implies a change in the sea level slope $(d h / d x)$ across the IFR on the order of $3 \mathrm{~cm}$ over $300 \mathrm{~km}$. By the equation of motion, a slope of this magnitude would give an acceleration $|d u / d t|=|g \cdot d h / d x| \approx 10 \mathrm{~cm} \mathrm{~s}^{-1}$ per day, which implies a major change of the IF-inflow within a day.

Such a rapid response would also require a rapid response of the SLH for the whole area, $A$, and the water from the IFinflow, certainly, does not spread throughout the Nordic Seas within a few days. That is not required, however. Changes in the SLH propagate through barotropic waves that move much faster than the water itself. Thus, a barotropic Kelvin wave over water of bottom depth $2000 \mathrm{~m}$ will have a speed exceeding $100 \mathrm{~m} \mathrm{~s}^{-1}$ and can circle the Nordic Seas counterclockwise in less than a day. Although hardly statistically significant, it is interesting to note that the highest correlations in Fig. 11 are along the path for such a wave propagating towards the area immediately downstream of the IFR. 
The response of a Kelvin wave is largest at the boundary, but it still extends about one barotropic Rossby radius into the open ocean (Gill, 1982). This is on the order of $1000 \mathrm{~km}$ for the Nordic Seas.

On time scales of weeks and months, SLH changes induced by IF-inflow variation can, therefore, be distributed across the entire Nordic Seas, but other exchanges, as well as wind, will affect the SLH of the Nordic Seas, also, and the northward limit of the altimetry data does not allow us to determine for how large a part of the Nordic Seas the SLH variations can be approximately represented by $h_{\mathrm{d}}$.

\section{Discussion}

An important point in this study is the high correlations between the measured IF-inflow and SLH variations (Table 1, Figs. 3 and 11). The question arises, whether this is due to geostrophy, solely, or also can help explain the local driving force. In the latter case, we also would like to know, what local and remote processes are involved.

\subsection{Geostrophy}

For time scales above one to a few days, we expect geostrophy to apply, implying a fall in SLH across the flow. Can this be the sole explanation for the high correlations between IF-inflow and SLH differences (Fig. 3b, Table 1)? Figure 11 shows that the correlation between IF-inflow and SLH extends over a wide area covering at least the entire Southern Nordic Seas. If the Atlantic water flow through the standard section were part of the internal circulation in the Nordic Seas, this basin-scale co-variability could be explained by geostrophy. The IF-inflow consists, however, of Atlantic water that has passed more or less directly from the IFR to the standard section. It has not been part of an internal circulation in the Nordic Seas, which is much more sluggish in the region east of Iceland, just before approaching the Faroe area (Perkins et al., 1998; Jakobsen et al., 2003).

Alternatively, one might consider the sea level variations to be caused by the IF-inflow variations. In that case, the water added by the IF-inflow would be expected to increase SLH downstream of the IFR. In addition, the Coriolis force would push water towards the right and increase SLH towards the Faroe Plateau. We would expect a positive correlation between IF-inflow and SLH over the inner part of the flow above the Faroe slope, in contrast to the observed, but there would be no reason for a strong SLH decrease far outside the flow, as observed (Fig. 11). Although valid, geostrophy is not a sufficient explanation for the observed relationship between sea level and the IF-inflow.

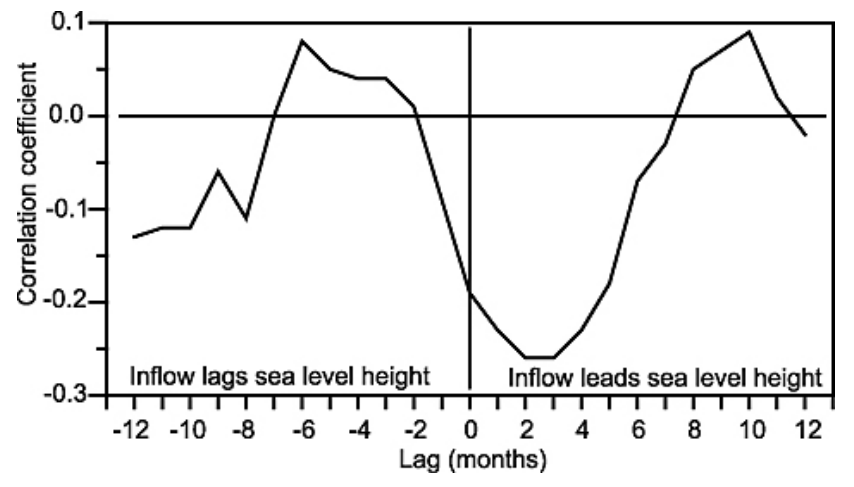

Fig. 12. Correlation coefficient between monthly averaged IFinflow and SLH upstream of the IFR, $h_{\mathrm{u}}$, lagged from -12 to +12 months.

\subsection{Local and remote forcing}

In Sect. 4.1, we argued that there has to be a local force that makes water cross the topographic barrier of the IFR and accelerate it towards the standard section. The highly variable wind forcing cannot explain the stable long-term IF-inflow but a positive correlation was found between eastward wind stress and IF-inflow (Sect. 4.3). This indicates that wind forcing does affect the kinetic energy and hence volume transport of the flow, but the correlation is weak. The difference in SLH across the IFR was, on the other hand, highly correlated with the IF-inflow (Table 1). Since this cannot be explained solely in terms of geostrophy (Sect. 6.1), it argues that sea level forcing provides the dominant local driving force for accelerating the IF-inflow across the IFR barrier.

Local sea level forcing must, however, be linked to remote processes that transport water towards or away from the IFR. From Eq. (1), a high IF-inflow can be generated in two ways: (1) a high value for the upstream SLH, $h_{\mathrm{u}}$, and (2) a low value for the downstream SLH, $h_{\mathrm{d}}$. The first of these is implicit in all mechanisms that involve remote forcing upstream of the IFR, such as the wind stress curl over an area in the North Atlantic (Orvik and Skagseth, 2003). In this case, remote forcing would move water towards the IFR area and maintain high $h_{\mathrm{u}}$ values that could maintain a high inflow. If the IF-inflow was maintained by an upstream mechanism, a positive correlation coefficient between $h_{\mathrm{u}}$ and IF-inflow would be expected, but the correlation coefficient is negative for weekly, monthly, and annually averaged data in the region directly upstream of the IFR (Fig. 11 and Table 1).

There is a delay involved in this, since $h_{\mathrm{u}}$ in Eq. (2) is the SLH upstream of the IFR while a water parcel was there, a couple of months before it arrives at the standard section (Appendix A). Even when lagged, however, the correlation coefficient between IF-inflow and $h_{\mathrm{u}}$ remains negative or non-significant (Fig. 12). The IF-inflow can not, therefore, be forced by $h_{\mathrm{u}}$. Rather, the IF-inflow seems to affect $h_{\mathrm{u}}$ inversely by removing water upstream of the IFR. 


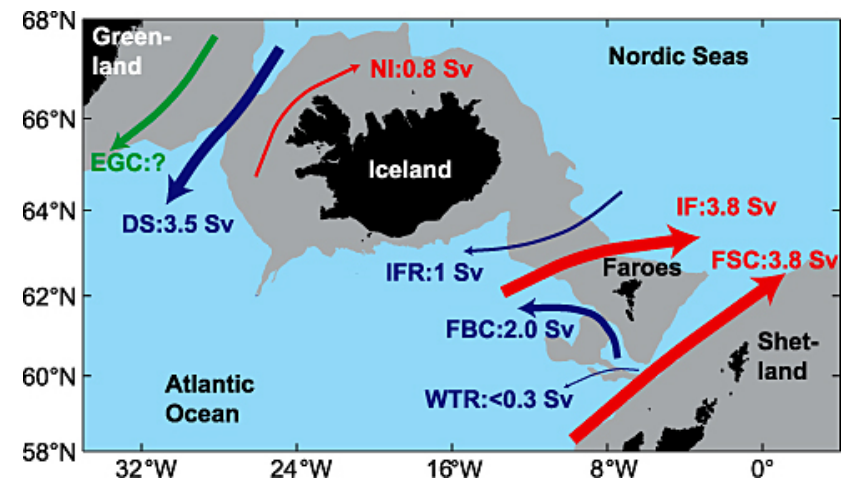

Fig. 13. Exchanges between the Nordic Seas and the Atlantic Ocean. Red arrows indicate Atlantic inflow to the Nordic Seas. Blue arrows indicate overflow, The green arrow indicates the surface-near outflow of the East Greenland Current. Volume transports are for the 1999-2001 period for the Atlantic inflow (Østerhus et al., 2005), for the DS-overflow (Macrander et al., 2005), and for the FBC-overflow (Hansen and Østerhus, 2007). For the two other overflow branches, typical values from the literature (Østerhus et al., 2008) are shown. The volume transport of the East Greenland Current is difficult to measure and not well known.

We conclude that the IF-inflow is not controlled mainly by processes upstream (southwest) of the IFR. The alternative type of sea level forcing is downstream forcing where lowering the downstream SLH, $h_{\mathrm{d}}$, should increase the IFinflow. For this mechanism, we expect a negative correlation coefficient between IF-inflow and $h_{\mathrm{d}}$ without appreciable delays, since both are measured in the same region. This is clearly supported by the observations on all time scales analyzed (Table 1). Variations in SLH downstream of the IFR generate the cross-ridge pressure gradients that dominate the variations of the IF-inflow.

These SLH variations extend over a wide region, perhaps most of the Nordic Seas area, and the response time is not much more than a day (Sect. 5). This implies that the IFinflow must be tightly linked to the other exchanges between the Nordic Seas and neighboring areas (Fig. 13) through the SLH. This also follows from the mass balance. If the average IF-inflow of $3.5 \mathrm{~Sv}$ were to be turned off without affecting other exchanges, the net outflow would lower the average SLH of the Nordic Seas by $12 \mathrm{~cm}$ within a day. Even relatively small imbalances between inflows and outflows will therefore rapidly develop sea level slopes across the IFR that can change the IF-inflow towards balance.

From the correlation methodology used above, inferences on forcing are restricted to the variations of the IF-inflow from its average value. These variations do, however, exceed the mean value in magnitude (monthly averages) and it is unlikely that the mean flow is maintained by a different process. Indeed, the highly variable local wind forcing is not a likely candidate. If the established relationship between $q$ and $h_{\mathrm{u}}-h_{\mathrm{d}}$ (Table 1, annual average, with $\alpha \approx 0.19 \mathrm{~Sv} \mathrm{~cm}^{-1}$ )

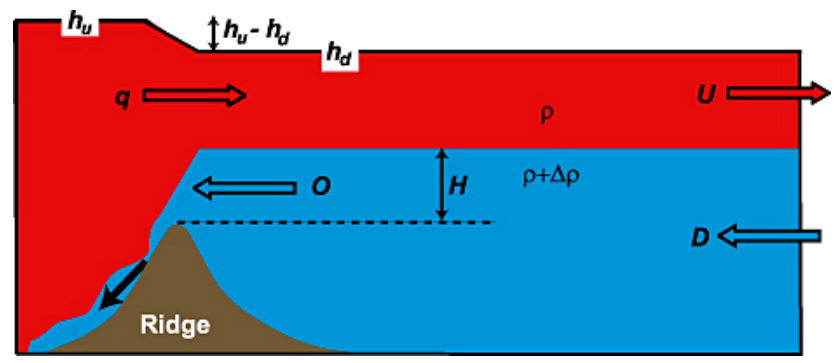

Fig. 14. A two-layer model for the region in the Southern Norwegian Sea with IF-inflow, $q$, FBC-overflow, $O$, net outflow from the upper layer, $U$, and inflow of dense water, $D$.

is extrapolated, the average IF-inflow of $3.5 \mathrm{~Sv}$ requires that an average sea level drop of $18 \mathrm{~cm}$ is continuously maintained across the IFR. Without an accurate mapping of the geoid, this is difficult to check against observations but, to our knowledge, there is no observational evidence against it.

This indicates that the average IF-inflow is driven by the same kind of forcing as has long been believed to maintain the average Bering Strait through-flow (Woodgate et al., 2005). There, short-term variability is higher and clearly linked to local wind stress, but the Bering Strait is an order of magnitude shallower than the IF-inflow and, therefore, much more sensitive to wind stress relative to the barotropic forcing of a sea level slope.

\subsection{Thermohaline processes}

If outflow from the Nordic Seas generates the sea level drop that maintains the IF-inflow then thermohaline processes must play a dominant role. The processes that generate outflow from the Nordic Seas include wind stress and estuarine forcing of the East Greenland Current (Stigebrandt, 2000), but they are dominated by thermohaline forcing. Of the $8.5 \mathrm{~Sv}$ of Atlantic water that enter the Nordic Seas (Østerhus et al., 2005), about $70 \%(6 \mathrm{~Sv})$ are estimated to leave as overflow (Macrander et al., 2005; Østerhus et al., 2008). The two weakest overflow branches (Fig. 13) seem to be highly variable but the two main branches, the DS-overflow and the FBC-overflow (Fig. 13) are very persistent (Macrander et al., 2005; Hansen and Østerhus, 2007). These two branches, alone, remove an average of $5 \mathrm{~Sv}$ from the Nordic Seas (Fig. 13), which would require less than two days to lower the average sea level of the Nordic Seas by $18 \mathrm{~cm}$, thereby maintaining the IF-inflow (Sect. 6.2).

This argument might lead one to expect a positive correlation between the IF-inflow and the neighboring FBCoverflow. In fact, we observe a negative correlation $(-0.47)$ for monthly averaged values. This apparent inconsistency arises because the FBC-overflow is affected by the SLH in the Nordic Seas in addition to the baroclinic forcing induced by sloping isopycnals (Olsen et al., 2008). This may be illustrated by a two-layer model extending from the Atlantic 
into the Southern Norwegian Sea (Fig. 14). This model is analyzed in Appendix B where it is shown that there would have been a positive correlation between IF-inflow and FBCoverflow if no other exchanges were involved. If all of the northeastward flowing water in the upper layer, $U$, (Fig. 14) had been converted into deep water, $D$, and fed back to the FBC-overflow, then the FBC-overflow would equal the IFinflow on time scales above a few days. In reality, however, only a fraction of $U$ ends up in $D$ and that implies that SLH variations induce a negative correlation between IFinflow and FBC-overflow on time scales extending towards the decadal, as shown in Appendix B.

The connection between the IF-inflow and other exchange branches is further complicated by the fact that they may affect one another. A compensating mechanism has been suggested between FBC-overflow and DS-overflow (Biastoch et al., 2003) and likewise an interaction between FSC-inflow and IF-inflow (Richter et al., 2009). A full treatment of this is hardly possible without a numerical model and a model study would also be necessary to understand in detail the variations observed, such as the 2002-2003 dip in the IFinflow (Fig. 3b).

Clearly, however, the outflows from the Nordic Seas, generated by estuarine and thermohaline processes, are sufficiently stable to induce a steady and strong lowering of the Nordic Seas SLH, unless compensated by inflow. This can explain the high stability that we observe for the IF-inflow and it is probably an important forcing mechanism for the two other Atlantic inflow branches, as well, although they may be more sensitive to additional forcing by the wind (Astthorsson et al., 2007; Sherwin et al., 2007).

These conclusions have implications for the feedback mechanism (Stommel, 1961) that has been suggested to couple processes in the Nordic Seas with the North Atlantic thermohaline circulation (THC). This feedback mechanism has been suggested to cause rapid climate shifts in paleodata (Broecker et al., 1985; Rahmstorff, 2002; McManus et al., 2004) and is implicit in suggestions for (Manabe and Stouffer, 1994) or against (Latif et al., 2000) anthropogenic weakening of the THC. Stimulation of dense water production through salt import is one of the loops in this mechanism. By showing that the overflow is a main generating mechanism for the IF-inflow, we have verified the other loop of the feedback for this exchange branch.

\section{Conclusions and outlook}

Based on our measurements from 1997-2008, we found an average volume transport of Atlantic water between Iceland and the Faroe Islands (IF-inflow) of $3.5 \pm 0.5 \mathrm{~Sv}$ with a negligible seasonal variation. No statistically significant trend was found in the IF-inflow and a weakening of this flow exceeding $10 \%$ during the observational period can be excluded with a probability of $97.5 \%$. Temperature and salinity in the core of the IF-inflow increased during the period.
We found statistically significant correlations between the measured IF-inflow and sea level height (SLH) variations on time scales from days to years, which we cannot explain by geostrophy solely. We interpret these high correlations to imply a local forcing of the IF-inflow that is dominated by the sea level drop across the Iceland-Faroe Ridge (IFR). This forcing is not generated by processes upstream (southwest) of the IFR, but rather by continual removal of water from the area downstream (northeast) of the IFR. We conclude that the relative stability of the IF-inflow derives from the processes that generate outflow from the Nordic Seas, especially the thermohaline processes that generate overflow.

This emphasizes the role of the IF-inflow as an integral component of the North Atlantic thermohaline circulation (THC). The THC is predicted to weaken during the 21 st century by most climate models (Solomon et al., 2007), but the models are not very precise in locating, where the weakening will occur. Our measurements indicate no weakening of the IF-inflow, as yet, but its role in transporting heat to the Arctic and salt to maintain the overflow and THC implies that continued monitoring of this flow should be an essential part of any early-warning system for global climate change.

\section{Appendix A}

\section{A simplified model of the IF-inflow}

We consider a parcel of Atlantic water (Fig. 6) that moves from upstream of the IFR to the standard section, conserving energy, and with constant density, $\rho$, Eq. (1). The pressure can be derived from the levels $z_{1}$ and $z_{2}$ and sea level heights $h_{1}$ and $h_{2}$ at the initial and final location of the parcel, respectively:

$$
\begin{aligned}
& 1 / 2 \rho u_{2}^{2}+\rho g z_{2}+\rho g\left(h_{2}-z_{2}\right) \\
& \quad=1 / 2 \rho u_{1}^{2}+\rho g z_{1}+\rho g\left(h_{1}-z_{1}\right)+w
\end{aligned}
$$

Whatever the path of the water parcel (Fig. 6), this implies that the change in kinetic energy is determined solely by the difference in sea level height (SLH) between the initial and final location and the work done by other forces, $w$ :

$$
1 / 2 \rho u_{2}^{2}+\rho g h_{2}=1 / 2 \rho u_{1}^{2}+\rho g h_{1}+w
$$

On the standard section, we assume the simplified geometry in Fig. 8 with constant eastward velocity, $u\left(=u_{2}\right)$. Consider a slice of the flow, of (small) thickness $L$, which will have a volume 1/2 BDL (Fig. 8). Each unit volume water parcel within this slice has to fulfill Eq. (A2), which, therefore, can be extended to comprise the whole slice. Care must be taken, however, because the SLH varies along the standard section due to geostrophy:

$h(y)=h_{\mathrm{d}}+\frac{f u}{g}\left(\frac{2}{3} B-y\right)$ 
where $y$ is the horizontal coordinate along the section and $f$ the Coriolis parameter. $B$ is the width of the current and $h_{\mathrm{d}}$ is the SLH just outside (north of) it. Current speed upstream is considerably weaker than at the standard section (Fig. 5) and we assume that the upstream kinetic energy can be neglected, so that $u_{1}=0$. If we also assume that the upstream SLH does not vary horizontally, $h_{1}=h_{\mathrm{u}}$ (Fig. 7), we get an energy equation for all the water within the slice:

$$
\begin{gathered}
1 / 2 \rho u^{2} \frac{\mathrm{BDL}}{2}+L \int_{\frac{-B}{3}}^{\frac{2 B}{3}} \rho g h(y) d(y) d y \\
=\rho g h_{u} \frac{\mathrm{BDL}}{2}+\mathrm{WL}
\end{gathered}
$$

where WL is the work done by external forces (wind stress and friction) on all the water in the slice from upstream to the standard section. This leads to a second order equation:

$u^{2}+\frac{10 f B}{9} u-2 g\left(h_{\mathrm{u}}-h_{\mathrm{d}}\right)-\frac{4 W}{\rho \mathrm{BD}}=0$

The appropriate solution is positive:

$u=\sqrt{2 g\left(h_{\mathrm{u}}-h_{\mathrm{d}}\right)+\frac{4 W}{\rho \mathrm{BD}}+\left(\frac{5 f B}{9}\right)^{2}}-\frac{5 f B}{9}$

At the equator, the last two terms would vanish but, north of the Faroes, they dominate the others, which can be employed to approximate Eq. (A6) by a series expansion, which to the first order gives:

$u=\frac{9 g}{5 f B}\left(h_{\mathrm{u}}-h_{\mathrm{d}}\right)+\frac{18}{5 \rho f B^{2} D} W$

With the model geometry (Fig. 8), $D=350 \mathrm{~m}$, and $B=$ $100 \mathrm{~km}$, an average volume transport of $3.5 \mathrm{~Sv}$, is equivalent to an average eastward velocity: $u=20 \mathrm{~cm} \mathrm{~s}^{-1}$, which is realistic (Fig. 1). With this choice of parameter values, the second order correction to Eq. (A7) is negligible. Equation (2) in Sect. 4.2 is then derived from this by multiplying with the area of the cross section.

When conditions are changing with time, it is necessary to take into account the delays involved. The value for $h_{\mathrm{u}}$ should be taken when the water parcel was upstream of the IFR, whereas $h_{\mathrm{d}}, u$, and $q$ are at the time when the parcel has reached the standard section. The magnitude of this delay can be estimated as the typical flushing time of the volume, $V$, of the region that the Atlantic water has to pass through on its way from upstream of the IFR to the standard section. A rough estimate is given as $T_{\text {flush }}=V / q$, where we use the region bordered by green lines in Fig. 5 and an average depth of $300 \mathrm{~m}$ to define $V$. This gives a flushing time of about a couple of months, which is probably somewhat overestimated. The effect of the local wind stress, $W$, is accumulated during this time and we therefore expect a delay from $W$ to $u$ and $q$ on the order of a month ( $\left.1 / 2 T_{\text {flush }}\right)$.

\section{Appendix B}

\section{A two-layer model of the Southern Norwegian Sea}

In the model (Fig. 14), we ignore the FSC-inflow and IFRoverflow (Fig. 13) and assume that only two sources feed this system: the IF-inflow, $q$, and a supply of dense water, $D$, from the north. Similarly, only two sinks drain the system: a northward flow, $U$, in the upper layer and the FBC-overflow, $O$. If SLH is kept fixed on the Atlantic side of the Ridge, the system may be considered controlled by the two exchanges, $U$ and $D$. We furthermore ignore local wind forcing over the Ridge. The IF-inflow is then given by Eq. (2) with $W=0$ :

$q=\alpha\left(h_{\mathrm{u}}-h_{\mathrm{d}}\right)$

The volume transport of FBC-overflow has been shown to be proportional to the pressure difference between both ends of the channel at the depth of the overflow current (Olsen et al., 2008). In the model, this implies that the FBC-overflow transport, $O$, is:

$O=\gamma\left(h_{\mathrm{d}}-h_{\mathrm{u}}+\varepsilon H\right) \quad$ with $\varepsilon \equiv \frac{\Delta \rho}{\rho}$

where $H$ is the height of the interface above the core of the overflow, $\Delta \rho$ the density difference between both layers, and $\gamma$ a constant that may be found by a regression analysis of observed FBC-overflow on $\left(h_{\mathrm{d}}-h_{\mathrm{u}}\right)$ from altimetry. We consider the two flows, $U$ and $D$, as specified functions of time and they therefore act as forcing functions. Wind forcing over the Southern Norwegian Sea may be included by its effect on $U$. If the surface area of the system considered is $A$, mass conservation of the total water column and the deeper layer, respectively, lead to the following equations:

$$
\begin{aligned}
& A \frac{d}{d t}\left(h_{\mathrm{d}}\right)=q-O-U+D \\
& \quad=(\alpha+\gamma)\left(h_{\mathrm{u}}-h_{\mathrm{d}}\right)-\gamma \varepsilon H-U+D \\
& A \frac{d H}{d t}=D-O=\gamma\left(h_{\mathrm{u}}-h_{\mathrm{d}}\right)-\gamma \varepsilon H+D
\end{aligned}
$$

We now assume that conditions on the Atlantic side of the Ridge, including the SLH value, $h_{\mathrm{u}}$, are constant, whereas $U$ and $D$ vary in time. Any disturbance can be seen as a (Fourier) superposition of periodic signals and we, therefore, consider the response to a periodic forcing of frequency $\omega$ :

$U=\bar{U}+\tilde{U} e^{i \omega t}$ and $D=\bar{D}+\tilde{D} e^{i \omega t}$

Since the equations are linear, the forced parameters, $h_{\mathrm{d}}, H$, $q$, and $O$ will behave similarly:

$$
\begin{gathered}
h_{\mathrm{d}}=\bar{h}_{\mathrm{d}}+\tilde{h}_{\mathrm{d}} e^{i \omega t} \wedge H=\bar{H}+\tilde{H} e^{i \omega t} \\
\wedge q=\bar{q}+\tilde{q} e^{i \omega t} \wedge O=\bar{O}+\tilde{O} e^{i \omega t}
\end{gathered}
$$

Inserting Eqs. (B5) and (B6) into Eqs. (B3) and (B4), we get two equations in which the constant and the time-varying 
terms have to balance separately. This allows us to determine the conditions for the average flow:

$\bar{q}=\bar{U} \wedge \bar{O}=\bar{D}$

and for the time-varying flow:

$$
\begin{aligned}
& A i \omega \tilde{h}_{\mathrm{d}}=-(\alpha+\gamma) \tilde{h}_{\mathrm{d}}-\gamma \varepsilon \tilde{H}-\tilde{U}+\tilde{D} \\
& A i \omega \tilde{H}=-\gamma \tilde{h}_{\mathrm{d}}-\gamma \varepsilon \tilde{H}+\tilde{D}
\end{aligned}
$$

which can be solved to give:

$$
\begin{aligned}
& \tilde{h}_{\mathrm{d}}=\frac{-i \omega A \tilde{D}+(i \omega A+\gamma \varepsilon) \tilde{U}}{\left(\omega^{2} A^{2}-\alpha \gamma \varepsilon\right)-i \omega A(\alpha+\gamma+\gamma \varepsilon)} \\
& \tilde{H}=\frac{-(\alpha+i \omega A) \tilde{D}-\gamma \tilde{U}}{\left(\omega^{2} A^{2}-\alpha \gamma \varepsilon\right)-i \omega A(\alpha+\gamma+\gamma \varepsilon)}
\end{aligned}
$$

Inserting these expression into Eqs. (B1) and (B2), we obtain:

$$
\begin{aligned}
& \tilde{q}=\frac{\alpha(\tilde{U}-\tilde{D})-i \gamma \frac{\alpha \varepsilon}{\omega A} \tilde{U}}{\alpha+\gamma+\gamma \varepsilon+i \omega A-i \gamma \frac{\alpha \varepsilon}{\omega A}} \\
& \tilde{O}=\frac{-\gamma(\tilde{U}-\tilde{D})+\gamma \varepsilon \tilde{D}-i \gamma \frac{\alpha \varepsilon}{\omega A} \tilde{D}}{\alpha+\gamma+\gamma \varepsilon+i \omega A-i \gamma \frac{\alpha \varepsilon}{\omega A}}
\end{aligned}
$$

We now introduce two time scales, $T_{0} \equiv 2 \pi A / \alpha$ and $T_{1} \equiv$ $2 \pi A /(\alpha \varepsilon)$. This allows us to approximate Eqs. (B12) and (B13) under three different conditions:

$$
\begin{aligned}
& \omega \gg \frac{2 \pi}{T_{1}} \wedge \tilde{U} \neq \tilde{D} \Rightarrow \tilde{q} \approx-\frac{\alpha}{\gamma} \tilde{O} \\
& \omega \ll \frac{2 \pi}{T_{1}} \Rightarrow \tilde{q} \approx \tilde{U} \wedge \tilde{O} \approx \tilde{D} \\
& \omega \ll \frac{2 \pi}{T_{0}} \wedge \tilde{U}=\tilde{D} \Rightarrow \tilde{q} \approx \tilde{O}
\end{aligned}
$$

To determine numerical values, we use $\alpha=0.15 \mathrm{~Sv} \mathrm{~cm}^{-1}$ (monthly average, Table 1). The value for $\gamma$, found by regression, was $0.05 \mathrm{~Sv} \mathrm{~cm}^{-1}$ (correlation coefficient: -0.67 ). Typical density differences between the upper and deeper layer are $\Delta \rho \approx 0.5 \mathrm{~kg} \mathrm{~m}^{-3}$, which gives $\varepsilon=5 \times 10^{-4}$. An appropriate value for the area, $A$, is more difficult to estimate and depends on the system considered. We focus on the local conditions and consider only the southeastern half of the Norwegian Basin with an area, $A \approx 4 \times 10^{11} \mathrm{~m}^{2}$. This gives $T_{0} \approx 2$ days and $T_{1} \approx 10$ years.

The case leading to Eq. (B16) can be illustrated by imagining that we simplify the system even more by assuming that all the water flowing out of the system in the upper layer, $U$, is immediately converted to denser water and fed back as deep flow, $D$. As long as time scales more than a few days are considered, Eq. (B16) should apply and the IF-inflow, $q$, will provide the water that afterwards is exported to the Atlantic as FBC-overflow, $O$. In this case we get a positive correlation between $q$ and $O$, as one might expect (Sect. 6.3)

For present-day conditions in the Southern Norwegian Sea, there is, however, no reason to expect equality between $U$ and $D$. For time scales approaching the decadal, we therefore expect Eq. (B14) to give the appropriate approximation. This explains why the observations show a negative correlation between the IF-inflow, $q$, and FBC-overflow, $O$ (Sect. 6.3). According to the model, we expect changes in the IF-inflow, $\Delta q$, to be related to simultaneous changes in the FBC-overflow, $\Delta O$ according to: $\Delta q=-\alpha / \gamma \cdot \Delta O \approx-3$. $\Delta O$. A neutral regression analysis, which seems most appropriate here (Emery and Thomson, 2001), on monthly averaged data gave $\Delta q=-2.8 \cdot \Delta O$. The model, thus, explains the observations very well and removes the apparent inconsistency. On longer time scales $\left(\omega \ll 2 \pi / T_{1}\right)$, Eq. (B15) indicates approach towards the steady state conditions (Eq. B7).

Acknowledgements. Funding for the measurements has been obtained from the Environmental Research Programme of the Nordic Council of Ministers (NMR) 1993-1998, from national Nordic research councils, from the European Framework Programs, and from the Danish DANCEA programme. Analysis and preparation of the manuscript has been supported by funding from the European Community's 7th framework programme (FP7/2007-2013) under grant agreement No. GA212643 (THOR: "Thermohaline Overturning - at Risk”, 2008-2012).

Edited by: M. Hecht

\section{References}

Astthorsson, O. S., Gislason, A., and Jonsson, S.: Climate variability and the Icelandic marine ecosystem, Deep-Sea Res. Pt. II, 54, 2456-2477, 2007.

Biastoch, A., Käse, R. H., and Stammer, D. B.: The sensitivity of the Greenland-Scotland Ridge Overflow to Forcing Changes, J. Phys. Oceanogr., 33, 2307-2319, 2003.

Broecker, W. S., Peteet, D. M., and Rind, D.: Does the oceanatmosphere system have more than one stable mode of operation?, Nature, 315, 21-26, 1985.

Emery, W. J. and Thomson, R. E.: Data Analysis Methods in Physical Oceanography, Second and Revised Edition, Elsevier Science B. V., Amsterdam, 638 pp., 2001.

Gill, A. E.: Atmosphere-Ocean Dynamics, Academic Press, London, 662 pp., 1982.

Hakkinen, S. and Rhines, P.: Decline of subpolar North Atlantic circulation during the 1990s, Science, 304, 555-559, 2004.

Hansen, B. and Østerhus, S.: North Atlantic - Nordic Seas Exchanges, Prog. Oceanogr., 45, 109-208, 2000.

Hansen, B. and Østerhus, S.: Faroe Bank Channel overflow 19952005, Prog. Oceanogr., 75, 817-856, 2007.

Hansen, B., Østerhus, S., Hátún, H., Kristiansen, R., and Larsen, K. M. H.: The Iceland-Faroe inflow of Atlantic water to the Nordic Seas, Prog. Oceanogr., 59, 443-474, 2003.

Hátún, H., Hansen, B., and Haugan, P.: Using an "Inverse Dynamic Method" to determine temperature and salinity fields from 
ADCP measurements, J. Atmos. Ocean. Tech., 21, 527-534, 2004.

Hátún, H., Sandø, A. B., Drange, H., Hansen, B., and Valdimarsson, H.: Influence of the Atlantic subpolar gyre on the thermohaline circulation, Science, 309, 1841-1844, 2005.

Ingvaldsen, R., Loeng, H., and Asplin, L.: Variability in the Atlantic inflow to the Barents Sea based on a one-year time series from moored current meters, Cont. Shelf Res., 22, 505-519, 2002.

Jakobsen, P. K., Ribergaard, M. H., Quadfasel, D., Schmith, T., and Hughes, C. W.: Near-surface circulation in the Northern North Atlantic as inferred from Lagrangian drifters: variability from the mesoscale to interannual, J. Geophys. Res., 108(C8), 3251, doi:10.1029/2002JC001554, 2003.

Kalnay, E., Kanamitsu, M., Kistler, R., Collins, W., Deaven, D., Gandin, L., Iredell, M., Saha, S., White, G., Woollen, J., Zhu, Y., Chelliah, M., Ebisuzaki, W., Higgins, W., Janowiak, J., Mo, K. C., Ropelewski, C., Wang, J., Leetmaa, A., Reynolds, R., Jenne, R., and Joseph, D.: The NCEP/NCAR 40-year reanalysis project, B. Am. Meteorol. Soc., 77, 437-471, 1996.

Latif, M., Roeckner, E., Mikolajewicz, U., and Ross, V.: Tropical stabilization of the thermohaline circulation in a greenhouse warming simulation, J. Climate, 13, 1809-1813, 2000.

Macrander, A., Send, U., Valdimarsson, H., Jónsson, S., and Käse, R. H.: Interannual changes in the overflow from the Nordic Seas into the Atlantic Ocean through Denmark Strait, Geophys. Res. Lett., 32, L06606, doi:10.1029/2004GL021463, 2005.

Manabe, S. and Stouffer, R. J.: Multiple-century response of a coupled ocean-atmosphere model to an increase of atmospheric carbon dioxide, J. Climate, 7, 5-23, 1994.

McManus, J. F., Francois, R., Gherardi, J.-M., Keigwin, L. D., and Brown-Leger, S.: Collapse and rapid resumption of Atlantic meridional circulation linked to deglacial climate changes, Nature, 428, 834-837, 2004.

Olsen, S. M., Hansen, B., Quadfasel, D., and Østerhus, S.: Observed and modelled stability of overflow across the GreenlandScotland ridge, Nature, 455, 519-522, 2008.

Orvik, K. A. and Skagseth, Ø.: The impact of the wind stress curl in the North Atlantic on the Atlantic inflow to the Norwegian Sea toward the Arctic, Geophys. Res. Lett., 30(17), 1884, doi:10.0129/2003GL017932, 2003.

Østerhus, S., Turrell, W. R., Jónsson, S., and Hansen, B.: Measured volume, heat, and salt fluxes from the Atlantic to the Arctic Mediterranean, Geophys. Res. Lett., 32, L07603, doi:10.1029/2004GL022188, 2005.
Østerhus, S., Sherwin, T., Quadfasel, D., and Hansen, B.: The overflow transport east of Iceland, in: Arctic-Subarctic Ocean Fluxes: Defining the role of the Northern Seas in climate, edited by: Dickson, R. R., Meincke, J., and Rhines, P., Springer Science and Business Media, Dordrecht, The Netherlands, chap. 18, 427-441, 2008.

Perkins, H., Hopkins, T. S., Malmberg, S.-A., Poulain, P.-M., and Warn-Varnas, A.: Oceanographic conditions east of Iceland, J. Geophys. Res., 103, 21531-21542, 1998.

Rahmstorff, S.: Ocean circulation and climate during the past 120000 years, Nature, 419, 207-214, 2002.

Richter, K., Furevik, T., and Orvik, K. A.: The effect of wintertime low pressure systems on the Atlantic inflow to the Nordic Seas, J. Geophys. Res., 114, C09006, doi:10.1029/2009JC005392, 2009.

Rossby, T., Prater, M. D., and Søiland, H.: Pathways of inflow and dispersion of warm waters in the Nordic seas, J. Geophys. Res., 114, C04011, doi:10.1029/2008JC005073, 2009.

Schauer, U. and Beszczynska-Möller, A.: Problems with estimation and interpretation of oceanic heat transport - conceptual remarks for the case of Fram Strait in the Arctic Ocean, Ocean Sci., 5, 487-494, doi:10.5194/os-5-487-2009, 2009.

Sherwin, T. J., Hughes, S. L., Turrell, W. R., Hansen, B., and Østerhus, S.: Wind-driven monthly variations in transport and the flow field in the Faroe-Shetland Channel, Polar Res., 27, 1-16, 2007.

Solomon, S., Qin, D., Manning, M., Chen, Z., Marquis, M., Averyt, K. B., Tignor, M., and Miller, H. L. (Eds.): Climate Change 2007: The Physical Science Basis. Contribution of Working Group I to the Fourth Assessment Report of the Intergovernmental Panel on Climate Change, Cambridge University Press, Cambridge, United Kingdom and New York, NY, USA, 2007.

Stigebrandt, A.: Oceanic freshwater fluxes in the climate system, in: The Freshwater Budget of the Arctic Ocean, edited by: Lewis, E. L., Lemke, P., Prowse, T. D., and Wadhams, P., NATO Science series, Kluwer Academic Publishers, Dordrecht, The Netherlands, chap. 1, 1-20, 2000.

Stommel, H.: Thermohaline convection with two stable regimes of flow, Tellus, 13, 224-230, 1961.

von Storch, H. and Zwiers, F. W.: Statistical Analysis in Climate Research, Cambridge Univ. Press, Cambridge, 1999.

Woodgate, R. A., Aagaard, K., and Weingartner, T. J.: A year in the physical oceanography of the Chukchi Sea: moored measurements from autumn 1990-1991, Deep-Sea Res. Pt. II, 5, 31163149, 2005. 